DOI: http://dx.doi.org/10.1590/S1414-40772016000200012

\title{
Evasão e retenção no curso de Biblioteconomia da UFRGS
}

\author{
Samile Andrea de Souza Vanz \\ Patrícia Mallmann Souto Pereira \\ Glória Isabel Sattamini Ferreira \\ Geraldo Ribas Machado
}

Resumo: Divulga resultados da pesquisa sobre evasão e retenção no curso de Biblioteconomia da Universidade Federal do Rio Grande do Sul (UFRGS) no período 2000/1 a 2009/2. Define aspectos do perfil do aluno deste Curso quanto a ingresso, renda familiar, motivação em relação ao curso, atividades remuneradas, utilização de benefícios da Pró-Reitoria de Assuntos Estudantis, motivação para a retenção, sentimento quanto à possibilidade de desistência do curso e quanto ao mercado de trabalho. Utiliza método quali-quantitativo, por meio de aplicação de questionários e entrevistas. Os resultados apontam um índice de evasão de quase $40 \%$ e de retenção de $46 \%$; há forte relação entre a vontade do aluno de cursar Biblioteconomia e o nível de conhecimento do currículo e das possibilidades de atuação profissional; a fragilidade na escolha do curso pode ser responsável por grande parte das retenções e evasões no curso; a necessidade de trabalhar representa grande influência na retenção e na evasão no curso; $50 \%$ dos alunos têm renda familiar inferior a 3,5 salários mínimos; há considerável utilização de benefícios concedidos pela universidade por parte dos alunos do curso; $86,2 \%$ dos alunos que evadiram sentiam-se insatisfeitos ou pouco satisfeitos com o curso; $66 \%$ dos alunos que evadiram do curso de Biblioteconomia ingressaram posteriormente em outro curso superior e estão cursando ou já se graduaram; a iniciativa para desistir e, de fato, a desistência, acontece logo no início do curso, especialmente no primeiro semestre. Conclui-se que no geral o aluno de Biblioteconomia da UFRGS tem grande responsabilidade com relação à sua família ou ao seu sustento próprio; muitos alunos são atraídos ao curso por interesses pelo ensino superior, mas sem conhecer mais profundamente a área de Biblioteconomia; os três primeiros semestres são decisivos no que tange a um trabalho específico para reduzir as retenções e acelerar as evasões, caso sejam inevitáveis.

Palavras-chave: Evasão universitária. Retenção universitária. Curso de Biblioteconomia. UFRGS.

\section{University dropout and grade retention at UFRGS Librarianship course}

Abstract: Reports the research results on dropout and grade retention of students in the course of Librarianship at the Federal University of Rio Grande do Sul (UFRGS) between 2000/1-2009/2. It defines aspects of the profile of the student of this course such as entry, family income, motivation towards the course, paid activities, use of benefits from the Office of Student Affairs, motivation for grade retention, feeling towards the possibility of cancellation of the course and in relation to the labor market. It uses a qualitative and quantitative method, by applying questionnaires and interviews. The results show a dropout rate of almost $40 \%$ and a grade retention of $46 \%$; there is a strong relationship between the student's willingness to attend the course of Librarianship and his/her level of knowledge about the curriculum and about the possibilities of professional practice. Weak reasons for the choice of the course may be responsible for a large percentage of dropouts and long-term students, as well as their need to work, because $50 \%$ of the students have family incomes below the rate of 3.5 minimum wages. There is considerable use of the benefits granted by the university among students of the course; $86.2 \%$ of students who have dropped out felt dissatisfied or only somewhat satisfied with the course; $66 \%$ of students who dropped out 
of the course of Librarianship later joined another course that they are attending or have already graduated; the choice to give up, and in fact the dropout occurs early in the course, especially along the first semester. It concludes that the average student of Librarianship at UFRGS has a great sense of responsibility towards his/her family or his/her own support; many students are attracted to the course by their interest for higher education, but without a deeper understanding of the field of librarianship; the first three semesters are decisive in regard to specific measures to reduce grade retention and accelerate dropouts, if unavoidable.

Key words: University dropout. Grade Retention. Librarianship Course. UFRGS.

\section{Introdução}

Uma questão que está entre as mais relevantes a serem enfrentadas pelas instituições de ensino superior (IES) é a evasão discente, especialmente pela universidade pública, que é financiada prioritariamente por investimentos governamentais. Grande parte dos cursos de graduação que formam profissionais aptos ao trabalho com informação está presente em universidades públicas, como é o caso dos cursos de Biblioteconomia. Dos 36 cursos brasileiros, 27 são ofertados por universidades públicas (ARAUJO; MARQUES; VANZ, 2011).

De maneira simultânea à ampliação de vagas anuais e à criação de novos cursos, as universidades públicas precisam atentar para o número de alunos que formam anualmente. O controle da equação ingressantes/concluintes deve ser rigoroso e prezar pelo equilíbrio, tendo em vista que o incremento da oferta de vagas resulta em aumento de alunos ingressantes, mas esta medida pode ser insuficiente caso ocorram muitos casos de evasão.

O problema da evasão discente é mundial e, segundo Silva Filho e colaboradores (2007), os dados sobre evasão nos cursos superiores do Brasil não diferem muito das médias internacionais. A evolução das taxas de evasão de cursos superiores brasileiros de 2006 a 2009 se manteve constante, em torno de $22 \%$, sendo em torno de $11 \%$ nas IES públicas e de $25 \%$ nas privadas, segundo cálculos do Instituto Lobo, com base em dados do Instituto Nacional de Estudos e Pesquisas Educacionais Anísio Teixeira (INEP) (LOBO, 2012).

Segundo Bardagi e Hutz (2009), com base na literatura, os índices de evasão são menores nos cursos mais valorizados, enquanto cursos menos valorizados e com baixo status apresentam os maiores índices. Isso pode ser explicado pelo fato de cursos como Medicina, Odontologia, Agronomia - listados, entre outros, como tendo as menores taxas de evasão em 2005 (SILVA FILHO et al., 2007) -, exigirem maior empenho do aluno para o ingresso via vestibular, o que reforça a certeza na escolha da carreira. Por outro lado, cursos como Biblioteconomia, que possuem menores taxas na relação candidato/vaga no concurso vestibular, possuem maiores índices de evasão. 
A situação geral entre os cursos da Universidade Federal do Rio Grande do Sul (UFRGS) não é diferente das demais IES brasileiras. De cada 100 alunos, só 68 chegam à formatura. Segundo entrevista da ex-reitora Wrana Panizzi (BELMONTE, 2003), diversos mecanismos foram adotados para que houvesse redução neste índice. Entre as soluções adotadas, a ex-reitora comenta a oferta de curso básico anterior à matrícula em disciplinas com alto nível de exigência, como a de Cálculo, possibilitando aos calouros um nivelamento extracurricular antes da matrícula na disciplina, que está presente na grade curricular de cerca de 30 cursos de graduação.

O curso de Biblioteconomia da UFRGS faz parte do Departamento de Ciências da Informação, e teve origem no curso Livre de Biblioteconomia, criado junto à então Universidade de Porto Alegre, em 1947, sob a justificativa da demanda por bibliotecas organizadas segundo técnicas científicas modernas. O currículo baseava-se na orientação teórico-pedagógica do curso de Biblioteconomia da Escola Livre de Sociologia e Política de São Paulo, com duração de dois anos e disciplinas de Bibliografia e Referência, Catalogação, Classificação, Organização e Administração de Bibliotecas e História do Livro e das Bibliotecas (OLIVEIRA; ROCHA, 2008).

Em 1954 o curso passou a funcionar sob a denominação de Curso Extraordinário de Biblioteconomia na Escola de Economia da Universidade. Sob a influência da criação do antigo Instituto Brasileiro de Biblioteconomia e Documentação (IBBD) e seu enfoque na documentação, em 1958 o curso passou a se denominar Curso de Biblioteconomia e Documentação. A Escola de Biblioteconomia e Documentação da UFRGS surgiu em 1966, marcada pela reforma universitária e pelas decorrentes alterações impostas aos currículos da universidade a partir de 1972 (SANTOS; SILVEIRA, 2000). Entre essas alterações está a incorporação das disciplinas do ciclo básico, a semestralização e o duplo ingresso. O curso, que atualmente oferece 70 vagas anuais, ostenta a melhor avaliação do Ministério da Educação (MEC) dentre os cursos de Biblioteconomia no Brasil.

O curso de Biblioteconomia da UFRGS já passou por algumas avaliações. Kruel (1988) analisou a evasão no curso no período 1979-1986. Dalla Zen e colaboradores (1986) realizaram pesquisa de avaliação do curso através da aplicação de questionário a professores, alunos, funcionários, egressos e vestibulandos que escolheram o curso em primeira opção. Em 1990 a então Comissão de Carreira de Biblioteconomia avaliou o curso e as disciplinas cursadas em 1988/2, através da opinião dos alunos matriculados a partir do segundo semestre. Posteriormente, novo estudo foi realizado por Ferreira, Tazima e Kruel (2000), através de questionários aplicados aos alunos em 1995. 
Os estudos realizados apresentaram resultados referentes à sua época. A partir do primeiro semestre de 2009, a Comissão de Graduação do curso iniciou os estudos para uma alteração em aspectos pontuais do currículo, cuja implantação aconteceu em março de 2011. Entre as alterações curriculares implantadas está a concentração das disciplinas obrigatórias e diversas eletivas no turno da manhã, possibilitando que o aluno cumpra as disciplinas obrigatórias neste turno e mais de dois terços dos créditos eletivos exigidos no currículo. A constante busca por professores para ministrar disciplinas obrigatórias de outros departamentos no prédio da Faculdade também foi sistematizada e pode ser apontada como uma das mudanças estruturais que beneficiaram o aluno do curso de Biblioteconomia, evitando assim o trânsito do aluno entre os campi da universidade. As mudanças no currículo do curso, o surgimento das cotas na UFRGS e as novas modalidades de apoio ao estudante oferecidas pela universidade justificam uma avaliação da situação atual.

Apesar do problema da evasão discente ser de importantes dimensões, no Brasil ainda há poucos estudos sobre suas características (CAMPELLO; LINS, 2008; BARDAGI; HUTZ, 2009), diferentemente do que acontece nos países desenvolvidos, em que os estudos sobre evasão são inúmeros e sistemáticos (LOBO, 2012). Dessa forma, o conceito de evasão discente não possui uma única definição consensual entre os autores que vêm tratando da questão, o que provoca dificuldades de comparação e pode induzir a interpretações enganosas (VELLOSO; CARDOSO, 2008).

Segundo Lobo (2012), há diferentes tipos de evasão: a evasão do curso, a da IES e a do sistema de ensino. Alguns autores, como Velloso e Cardoso (2008) salientam que a mobilidade estudantil (isto é, a evasão do curso mas não da IES, ou mesmo da IES mas não do sistema) é um processo natural no sistema universitário, não sendo necessariamente ruim. Lobo $(2012$, p. 8) explica que muitas IES não consideram evasão propriamente dita se o aluno mudar de curso, mas permanecer na IES, assim como "[...] não consideram evasão se a vaga deixada por um aluno que mudou de curso, ou de IES, for preenchida por outro aluno que venha por transferência, ou como matrícula de graduado."

Faz-se necessário prestar especial atenção aos alunos considerados retidos, pois estes podem ser vistos como evadidos em potencial, além de terem um custo para as IES, especialmente públicas, e para a sociedade. Segundo Cesarino e colaboradores (1987, p. 161):

A retenção traz consigo problemas pedagógicos e administrativos. Do ponto de vista pedagógico, o aluno perde a visão do conhecimento 
integrado que o currículo padrão pretende garantir. A visão da área profissional, adquirida através de um processo de formação fragmentado e algumas vezes bastante distanciado no tempo, pode levar a distorções na aquisição do conhecimento. Do ponto de vista administrativo, lida-se com a dificuldade de previsão de número de alunos por turma, turmas excessivamente grandes, turmas heterogêneas, etc.

Preocupada com os índices de evasão e retenção da UFRGS, a Pró-reitoria de Graduação da UFRGS propôs, em 2010, um edital para pesquisas acerca do tema. A Coordenação do Curso de Graduação em Biblioteconomia assumiu o projeto que teve como objetivo investigar os motivos determinantes da evasão e da retenção dos alunos do curso de Biblioteconomia da Universidade Federal do Rio Grande do Sul (UFRGS), no período de 2000/1 a 2009/2. O objetivo deste artigo é divulgar alguns dos resultados desta pesquisa.

\section{Procedimentos metodológicos}

A pesquisa sobre evasão e retenção no curso de Biblioteconomia da UFRGS desenvolveu-se em duas etapas. A primeira consistiu na coleta de dados quantitativos através do Sistema de Graduação da UFRGS (SISGRAD/UFRGS) e aplicação de questionários para alunos evadidos e em curso. A segunda etapa consistiu em uma coleta de dados qualitativos, por meio da realização de entrevistas, que se destinou a explicar e aprofundar questões levantadas na etapa anterior.

A coleta de dados quantitativa iniciou em 2010 através do SISGRAD/ UFRGS para coleta de dados referentes aos alunos vinculados ao curso no período de 2000/1 a 2009/2, permitindo a caracterização destes alunos, isto é, as datas de entrada e de saída do curso, a forma de entrada, além de outros dados gerais de identificação. Após isso foram construídos dois instrumentos de pesquisa, um para os alunos em curso e outro para alunos evadidos, com o objetivo de levantar informações não obtidas no SISGRAD/UFRGS. O convite para participar da pesquisa, respondendo aos questionários disponíveis no Google Docs, foi enviado por e-mail a todos os alunos vinculados ao curso de Biblioteconomia em março de 2011. Os alunos evadidos foram localizados através do e-mail disponível no SISGRAD e através de convites feitos pelas redes sociais Orkut e Facebook, além da pesquisa de e-mail na internet via ferramenta de busca Google.

Para ampliar o total de respostas dos alunos em curso, procedeu-se também a uma coleta pessoal de respondentes nas salas de aula do curso de Biblioteco- 
nomia em março de 2011. Foram convidados a participar da pesquisa cerca de 350 alunos matriculados e 268 alunos evadidos. Obtiveram-se 209 respostas dos alunos em curso e 88 respostas dos evadidos.

As perguntas existentes nos questionários não eram de resposta obrigatória, de modo que nem todas as questões obtiveram $100 \%$ de respostas. Algumas perguntas eram de múltipla escolha, justificando o número elevado de respostas. As respostas dos questionários foram adicionadas ao banco de dados dos alunos em curso, no Microsoft Excel 2007, e o tratamento quantitativo foi realizado através deste software e do SPSS versão 18. Desses resultados apurados, são apresentadas e analisadas neste artigo as principais características dos alunos do curso de Biblioteconomia, o perfil do aluno evadido e as impressões dos mesmos acerca do curso.

Foram considerados evadidos os alunos que se encontravam desligados do curso, por diferentes motivos: desligamento por abandono, afastamento por trancamento, desistência de vaga, jubilamento, transferência interna, transferência para outra universidade e falecimento, já que houve uma incidência.

Em relação à retenção discente, a questão também é problemática, uma vez que não há parâmetros estabelecidos para sua definição e estudo. Cesarino e colaboradores (1987, p. 161), que estudaram a retenção no curso de Biblioteconomia da Universidade Federal de Minas Gerais, definem o aluno retido como “[...] aquele que, por qualquer motivo, não terminou ou não teria condição de terminar o curso de graduação no tempo mínimo previsto pelo currículo padrão [...]". Martucci e Nastri (1990), que estudaram a evasão e a retenção na Escola de Biblioteconomia e Documentação de São Carlos, também adotam essa definição. Ambos consideram trancamento de matrícula como uma forma de retenção, e não de evasão, como é considerado nesta pesquisa. Há outros casos em que a retenção pode ser medida de acordo com níveis de aproveitamento do aluno no curso, como taxas de reprovação, abandono, trancamento etc.; ou ainda a partir de limites toleráveis para o fenômeno. Nesta pesquisa foi estudado o conjunto dos alunos que estavam cursando a faculdade, mas foram considerados alunos retidos aqueles que, no momento da análise dos dados, ultrapassavam o limite previsto para conclusão do curso -8 semestres.

Após interpretação dos dados quantitativos, partiu-se para a segunda etapa da pesquisa, qualitativa, a fim de aprofundar algumas questões. $O$ instrumento utilizado nesta etapa foi entrevista pautada por um roteiro composto por questões objetivas (com o intuito de se obter os perfis das amostras) e questões subjetivas, aplicado a uma amostra dos alunos em curso e a uma amostra dos alunos evadidos. 
Para os alunos em curso, selecionou-se uma amostra estratificada proporcional de 9 indivíduos, respeitando os estratos pré-definidos entre o grupo de alunos matriculados no curso de Biblioteconomia da UFRGS (cerca de 350). Para o grupo de 268 alunos evadidos localizados definiu-se a amostra através da técnica não probabilística denominada de amostragem por acessibilidade ou por conveniência, que se caracteriza por selecionar os elementos a que se tem acesso (GIL, 2007). Essa opção foi feita devido à dificuldade em se ter acesso aos sujeitos, assim como pela sua pouca disponibilidade em realizar a entrevista. Para contato com os sujeitos, foi enviado um e-mail a todos os componentes da população de evadidos convidando-os a responder à entrevista, e a amostra foi definida a partir dos que se dispuseram a um encontro presencial, totalizando 7 entrevistas. Todos eles fizeram parte da primeira parte da pesquisa e responderam ao questionário.

Antes da realização das entrevistas, os sujeitos assinaram um termo de consentimento livre e esclarecido, após serem esclarecidos sobre os objetivos da pesquisa e sobre o seu anonimato em relação às informações fornecidas.

\section{Resultados e discussão}

Foram identificados 894 indivíduos vinculados ao curso de Biblioteconomia no SISGRAD/UFRGS no período 2000/1 a 2009/2, conforme apresenta a Tabela 1 a seguir:

\section{Tabela 1 - Situação dos alunos do curso de Biblioteconomia/UFRGS entre 2000/1 a 2009/2}

\begin{tabular}{c|c|c}
\hline \multirow{2}{*}{ Situação } & \multicolumn{2}{c}{ Frequência } \\
\cline { 2 - 3 } & Absoluta & Relativa (em \% \\
\hline Diplomação & 272 & 30,4 \\
Cursando & 279 & 31,2 \\
Abandono & 174 & 19,5 \\
Afastamento por trancamento & 23 & 2,6 \\
Desistência de vaga & 106 & 11,9 \\
Falecimento & 1 & 0,1 \\
Jubilamento & 4 & 0,4 \\
Transferência interna & 31 & 3,5 \\
Transferência para outra IES & 4 & 0,4 \\
\hline Total & 894 & 100,0 \\
\hline
\end{tabular}

Fonte: SISGRAD/UFRGS 
Observa-se que $31,2 \%$ dos alunos vinculados ao SISGRAD/UFRGS entre 2000/1 e 2009/1 estavam cursando Biblioteconomia no período, enquanto 30,4\% já haviam sido diplomados. O restante, quase $40 \%$, encontrava-se em situação considerada de evasão: abandono, afastamento por trancamento, desistência de vaga, falecimento, jubilamento, transferência interna e transferência para outra universidade.

Tal resultado se aproxima ao apresentado pela Escola de Biblioteconomia de São Carlos, que relata $36,43 \%$ de evasão e $12,86 \%$ de retenção ${ }^{1}$ no período de 1985 a 1989 (MARTUCCI; NASTRI, 1990). Conforme as autoras, os principais motivos da evasão do curso estão relacionados a causas externas, como a falta de informação sobre o curso e problemas de incompatibilidade de horário do curso com o trabalho, bem como problemas particulares.

A citação de "problemas particulares" pode ser analisada pela situação sócio-econômica dos pais, ressaltando-se as condições da mulher, tendo em vista que a população estudantil é essencialmente feminina (situação como casamento, gravidez, guarda dos filhos, administração doméstica, etc., podem influenciar na decisão de desistência). Também foi significativa a desistência pelo "ingresso em outro curso superior", o que parece demonstrar que o Curso de Biblioteconomia se enquadrava, informalmente como $2^{\circ}$ opção ou como garantia de ingresso em um curso superior (p. 70).

$\mathrm{Na}$ Universidade Federal de Minas Gerais (UFMG), a evasão perfez 33\% das matrículas nos anos 1982 e 1983, enquanto a retenção ${ }^{2}$ representava 48\% dos alunos em 1984 (CESARINO et al., 1987). O principal fator para a retenção indicado pelos alunos participantes da pesquisa foi a incompatibilidade de horário das disciplinas com o seu horário de trabalho e/ou estágio. Mas os autores advertem que as possíveis causas de retenção não estão voltadas apenas para os fatores externos e os problemas pessoais, mencionados na pesquisa anterior, mas também a problemas como "interesse pela disciplina, motivos para a escolha do curso e expectativa em relação a profissão de bibliotecário. " (CESARINO et al., 1987, p. 164).

Ao analisar o perfil do aluno matriculado se pode identificar a retenção e os motivos para isso. Conforme o ano de ingresso, os alunos que estavam matriculados no curso de Biblioteconomia da UFRGS em 2011/1 e responderam ao questionário estavam assim distribuídos, segundo representa a Tabela 2:

1 A definição de retenção utilizada no estudo de Martucci e Nastri (1990, p. 61) difere-se do adotado nesta pesquisa, sendo considerada “[...] reprovação por aproveitamento ou frequência; trancamento de matrícula e matrícula por créditos parciais [...]".

2 Definição para retenção no estudo de Cesarino e outros (1987, p. 160) “[...] alunos que permaneciam na universidade mais tempo do que o esperado [...]”. 


\section{Tabela 2 - Ano de ingresso dos alunos do curso de Bibliot economia/UFRGS matriculados em 2011/1}

\begin{tabular}{c|cc}
\hline \multirow{2}{*}{ Ano } & \multicolumn{2}{|c}{ Frequência } \\
\cline { 2 - 3 } & Absoluta & Relativa (em \%) \\
\hline 2000 & 1 & 0,5 \\
2003 & 3 & 1,5 \\
2004 & 7 & 3,5 \\
2005 & 4 & 2,0 \\
2006 & 22 & 11,0 \\
2007 & 55 & 27,7 \\
2008 & 71 & 35,7 \\
2009 & 36 & 18,1 \\
\hline Total & 199 & 100,0 \\
\hline
\end{tabular}

Fonte: Dados da pesquisa

Caso fosse adotada a definição de retenção de Cesarino e colaboradores (1987) e Martucci e Nastri (1990), um número considerável dos alunos matriculados em 2011/1 é considerado retido. Esses alunos estão distribuídos entre os com ingresso, em 2000, aos alunos com ingresso em 2007/1, representando $46,2 \%$, tendo em vista que o curso tem duração de oito semestres.

Contudo, há alunos extremamente atrasados, com entrada nos anos 2000, 2003 e 2004. Analisando individualmente os 11 alunos nessa situação, obtém-se um grupo semelhante, mas com motivos diferentes para justificar sua retenção. Entre eles, pode-se citar o alto índice de reprovação por faltas e aproveitamento, múltiplos pedidos de trancamento e licenças saúde, baixo número de disciplinas cursadas por semestre e episódios de abandono e readmissão no curso.

A Tabela 3 apresenta a média de idade e as idades mínimas e máximas dos alunos evadidos, diplomados e daqueles que estavam matriculados entre 2000/1 e 2009/2, cursando Biblioteconomia no momento da coleta de dados, em 2011/1:

Observa-se que para os três grupos de alunos a idade mínima é muito semelhante, em torno de 17 anos ao entrar, indicando que existem alunos muito jovens frequentando o curso. Alguns alunos também se formam muito jovens, visto que a idade média de diplomados é 20 anos. Ao se analisar a coluna de idade máxima, por outro lado, observa-se que o curso é frequentado também 
por idosos, conforme resultados que mostram alunos que iniciam e se diplomam com idade em torno de 60 anos. A coluna de idade média deve ser observada com ressalvas visto que a diferença entre idades mínimas e máximas é muito grande, o que pode ocasionar distorção nos valores médios.

\section{Tabela 3 - Idade média, mínima e máxima dos alunos do curso de Biblioteconomia/UFRGS matriculados em 2011/1}

\begin{tabular}{c|c|c|c|c|c|c}
\hline \multirow{2}{*}{ Idade (em anos) } & \multicolumn{2}{|c|}{ Evadidos } & \multicolumn{2}{c|}{ Cursando } & \multicolumn{2}{c}{ Diplomados } \\
\cline { 2 - 7 } & Entrada & Saida & Entrada & Saida & Entrada & Saida \\
\hline \multirow{2}{*}{ Mínima } & 16,7 & 16,7 & 17,4 & - & 17,0 & 20,1 \\
Máxima & 58,4 & 62,2 & 56,1 & - & 64,4 & 68,9 \\
Média & 26,6 & 28,5 & 27,7 & - & 26,1 & 31,7 \\
\hline
\end{tabular}

Fonte: Dados da pesquisa

Nota: a idade apresenta-se em anos e meses

Em relação ao gênero, a grande maioria dos alunos do curso de Biblioteconomia é composta por mulheres, que representam $77 \%$ dos alunos em curso. O perfil difere do apresentado pela UFMG em 1984, que relatou que o curso era formado por $94,5 \%$ de mulheres e $80,8 \%$ solteiras. O Gráfico 1 apresenta maiores detalhes:

Observa-se neste gráfico que $43 \%$ dos alunos do grupo de evadidos são homens, indicando uma tendência masculina a evadir, muito mais do que se diplomar ou se manter em curso.

Os dados obtidos em relação ao estado civil dos alunos mostram que $67 \%$ dos alunos são solteiros, $28,6 \%$ são casados ou com união estável e 4,4\% são separados. Em relação ao local de residência, $65,6 \%$ dos alunos residem em Porto Alegre e 27,4\% em municípios da Grande Porto Alegre. A concentração de alunos residentes em Porto Alegre e Grande Porto Alegre reflete-se na quase inexistência de profissionais bibliotecários para ocupar as vagas de emprego no interior do Estado, conforme dados do Conselho Regional de Biblioteconomia da $10^{\text {a }}$ Região. Apesar da grande oferta de emprego no interior do Estado, poucos são os alunos que optam por mudar de cidade após a formatura. 
Gráfico 1 - Alunos do curso de Biblioteconomia/UFRGS evadidos, cursando e diplomados por gênero

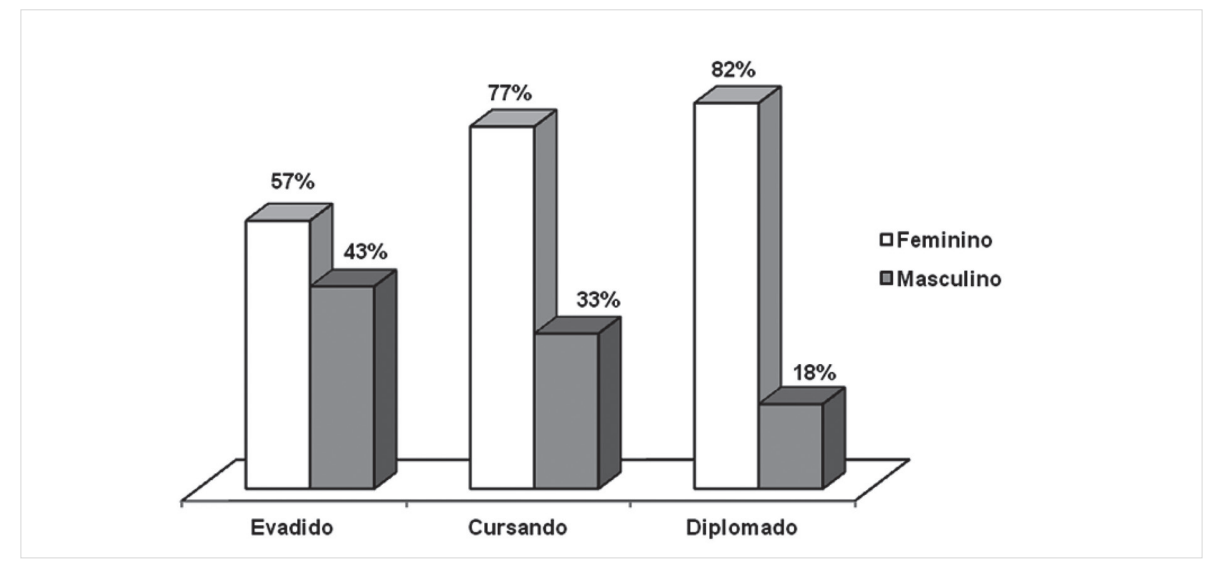

Fonte: Dados da pesquisa

Quanto à renda familiar, os dados apurados são apresentados na Tabela 4.

Tabela 4 - Renda familiar dos alunos do curso de Biblioteconomia/ UFRGS matriculados em 2011/1

\begin{tabular}{c|cc}
\hline \multirow{2}{*}{ Salários mínimos } & \multicolumn{2}{|c}{ Frequência } \\
\cline { 2 - 3 } & Absoluta & Relativa (em \%) \\
\hline Até 1 & 13 & 6,5 \\
De 1 a 2 & 34 & 16,9 \\
De 2 a 3 & 38 & 18,9 \\
De 3 a 5 & 59 & 29,4 \\
De 5 a 10 & 36 & 17,9 \\
De 10 a 20 & 14 & 6,9 \\
Mais de 20 & 2 & 1,0 \\
Sem rendimento & 5 & 2,5 \\
\hline Total geral & 201 & 100,0 \\
\hline
\end{tabular}

Fonte: Dados da pesquisa

Nota: salário mínimo em 2011/1 - R\$ 545,00 
Em relação à renda familiar dos alunos matriculados no curso de Biblioteconomia, observa-se que a maior incidência encontra-se no intervalo de 3 a 5 salários mínimos, correspondendo a 29,4\% dos 201 alunos. Um indicador relevante é a renda familiar mediana, isto é, 50\% das famílias têm renda inferior a 3,5 salários mínimos, o que representa uma grande concentração de alunos em famílias de baixa renda. Cerca de metade dos respondentes tem participação na renda familiar, resultado que indica grande responsabilidade por parte do aluno com relação à sua família.

Esse fato pode explicar em certa medida o alto índice de retenção discente no curso, assim como o mesmo fato foi identificado em outros cursos de Biblioteconomia. Segundo achados de Cesarino e colaboradores (1987, p. 159), "A análise do aluno retido mostra que ele vem de uma classe social pouco privilegiada, com baixa renda familiar, trabalhando por necessidade econômica.”. Martucci e Nastri (1990, p. 75) encontraram resultado semelhante, sendo os motivos para a retenção "[...] mais relacionados a fatores externos à instituição, decorrentes das condições socioeconômicas do corpo discente.". Esses alunos são considerados os casos mais graves, pois, como constataram Velloso e Cardoso (2008) em pesquisa sobre evasão na Universidade de Brasília, alunos com baixo rendimento tendem a se evadir em proporções bem maiores do que alunos com rendimento elevado.

Os resultados acerca da escolaridade da família dos alunos matriculados em 2011/1 reiteram o baixo nível socioeconômico, como mostra a Tabela 5. Observa-se que o número total de respostas variou de 206 respondentes para a escolaridade do pai, 208 para a da mãe e 143 para a do cônjuge:

Observa-se que pai e mãe de cerca de $28 \%$ dos alunos respondentes possuem o ensino fundamental incompleto, resultado que demonstra o baixo índice educacional da família do aluno e pode interferir na motivação e incentivo para a conclusão do curso. O ensino médio completo também representa um índice alto $(28 \%)$ de escolaridade de pai e mãe do aluno. Somando-se as respostas obtém-se em torno de $72 \%$ dos alunos cujo pai e mãe têm escolaridade até o ensino médio completo. Em relação ao curso superior, os resultados perfazem cerca de $20 \%$ para o pai e $17 \%$ para a mãe. A existência de pais com curso de pós-graduação concluído é inexpressiva no conjunto de respondentes.

A situação do cônjuge é aparentemente melhor, visto que 13,3\% dos alunos responderam que o cônjuge possui ensino superior incompleto, 18,1\% responderam que possuem superior completo e $6,3 \%$ possui pós-graduação completa. A opção "não sei" recebeu $47 \%$ das 143 respostas, fato bastante intrigante. 


\section{Tabela 5 - Escolaridade da família dos alunos matriculados em 2011/1}

\begin{tabular}{c|c|c|c|c|c|c}
\hline \multirow{2}{*}{ Escolaridade } & \multicolumn{2}{|c|}{ Pai } & \multicolumn{2}{c|}{ Mãe } & \multicolumn{2}{c}{ Cônjuge } \\
\cline { 2 - 7 } & Total & $\%$ & Total & $\%$ & Total & $\%$ \\
\hline Ensino Fundamental incompleto & 58 & 28,2 & 60 & 28,8 & 1 & 0,7 \\
Ensino Fundamental completo & 21 & 10,2 & 12 & 5,9 & 1 & 0,7 \\
Ensino Médio incompleto & 8 & 3,9 & 22 & 10,6 & 3 & 2,1 \\
Ensino Médio completo & 59 & 28,6 & 60 & 28,8 & 15 & 10,5 \\
Ensino Superior incompleto & 17 & 8,2 & 14 & 6,7 & 19 & 13,3 \\
Ensino Superior completo & 25 & 12,1 & 20 & 9,6 & 26 & 18,1 \\
Pós-graduação incompleta & - & - & 1 & 0,5 & 2 & 1,3 \\
Pós-graduação completa & 4 & 1,9 & 5 & 2,4 & 9 & 6,3 \\
Sem instrução & 4 & 1,9 & 11 & 5,3 & - & - \\
Não sei & 10 & 5,0 & 3 & 1,4 & 67 & 47,0 \\
\hline Total & 206 & 100,0 & 208 & 100,0 & 143 & 100,0
\end{tabular}

Fonte: Dados da pesquisa

Ao serem questionados sobre as atividades extracurriculares, observou-se que, além de empregos fora da área do curso, um número considerável de alunos realiza estágios extracurriculares e sustenta-se sozinho com essa renda. Quando é analisado o tipo de atividade remunerada realizada via faculdade, destaca-se que $32,9 \%$ dos alunos realizam estágios, que são atividades melhor remuneradas do que os outros tipos descritos na Tabela 6 :

Um resultado inesperado é o fato de que $46,8 \%$ dos alunos responderam não exercer atividade remunerada, visto que há grande oferta de vagas na faculdade. Contudo, esse grande percentual pode ser resultado de respostas provenientes daqueles alunos que trabalham em atividades remuneradas não relacionadas ao curso. Também pode-se considerar o exercício de atividades voluntárias.

Em relação ao uso dos benefícios da Secretaria de Assistência Estudantil (SAE), atualmente Pró-Reitoria de Assistência Estudantil (PRAE), 32,2\% dos alunos utilizam. Quando especificados quais são os benefícios utilizados, 
observa-se que, dos 66 alunos que utilizam o benefício, 37,9\% utilizam o auxílio material, $53,0 \%$ o auxílio transporte, $54,6 \%$ a bolsa SAE, $53,0 \%$ o programa saúde e $92,4 \%$ o desconto nos restaurantes universitários (RUs). Outros benefícios menos utilizados são o auxílio creche (3\%), a bolsa permanência $(15,1 \%)$, a bolsa REUNI e a casa do estudante (ambas com 16,7\%).

\section{Tabela 6 - Tipo de atividade remunerada por parte dos alunos matriculados em 2011/1}

\begin{tabular}{|c|c|c|}
\hline \multirow{2}{*}{ Atividade } & \multicolumn{2}{|c|}{ Frequência } \\
\hline & Absoluta & Relativa (\%) \\
\hline Bolsa SAE & 1 & 0,5 \\
\hline Estágio & 68 & 32,9 \\
\hline Iniciação Científica & 13 & 6,3 \\
\hline Monitoria & 18 & 8,7 \\
\hline Outro tipo & 10 & 4,8 \\
\hline Nenhuma & 97 & 46,8 \\
\hline Total & 207 & 100,0 \\
\hline
\end{tabular}

Fonte: Dados da pesquisa

No que tange ao tempo de utilização de tais benefícios, observa-se que a maioria dos alunos $(42,4 \%)$ os utilizam por mais de quatro semestres, indicando a real necessidade de continuidade da oferta desses benefícios aos alunos ao longo de todo o curso. Também observou-se que $70,5 \%$ dos alunos do curso de Biblioteconomia são provenientes de escola pública e, destes, $76,9 \%$ utilizam os benefícios SAE. Tal resultado pode indicar alguma relação entre a necessidade de uso dos benefícios e a implantação das cotas na universidade.

Quando questionados sobre o atraso no curso, configurando uma situação de retenção, $65,8 \%$ dos alunos apontaram como principal motivo os fatores relacionados ao contexto pessoal, conforme as duas primeiras respostas da Tabela 7 .

Isso ratifica o indicador de que problemas pessoais, externos à instituição, são as preponderantes causas de atraso do aluno no curso, sendo essas as questões que devem ser mais atentamente observadas e trabalhadas pela Coordenação do Curso junto aos alunos. Contudo, algumas questões causadoras das primeira, segunda e quarta respostas podem já estar sendo amenizadas pela mudança curricular implantada em 2011, com medidas como: redução da carga horária total do curso, diminuindo a repetição de conteúdos; possibilidade de todos 
os créditos obrigatórios e dois terços dos eletivos serem cursados no turno da manhã; possibilidade do aluno matricular-se em turmas nos turnos da tarde e noite nas disciplinas comuns aos três cursos de graduação do Departamento (Biblioteconomia, Arquivologia e Museologia); entre outras.

\section{Tabela 7 - Motivos para o atraso no curso por parte dos alunos do curso de Biblioteconomia/UFRGS matriculados em 2011/1}

\begin{tabular}{l|c|c|c}
\hline \multirow{2}{*}{ Motivo } & \multicolumn{3}{c}{ Frequência } \\
\cline { 2 - 4 } & Absoluta & Relativa (em \%) & Acumulada (\%) \\
\hline $\begin{array}{l}\text { Não estar conseguindo compatibilizar o curso com } \\
\text { outras demandas particulares }\end{array}$ & 31 & 26,5 & 26,5 \\
$\begin{array}{l}\text { Não estar conseguindo compatibilizar o curso com } \\
\text { trabalho }\end{array}$ & 46 & 39,3 & 65,8 \\
$\begin{array}{l}\text { Não estar gostando do curso, deixando disciplinas para } \\
\text { trás ou trancando }\end{array}$ & 10 & 8,6 & 74,4 \\
$\begin{array}{l}\text { Precisou de mais tempo para conseguir aproveitar } \\
\text { melhor o curso }\end{array}$ & 26 & 22,2 & 96,6 \\
$\begin{array}{l}\text { Teve uma oportunidade de estudar fora da UFRGS } \\
\text { (mobilidade / convênios) }\end{array}$ & 4 & & 100,0 \\
\hline \multicolumn{1}{c|}{ Total } & 117 & 100,0 & - \\
\hline
\end{tabular}

Fonte: Dados da pesquisa

Com o objetivo de solucionar problemas e orientar os alunos é necessário um trabalho específico com aqueles que informaram não estar gostando do curso, a fim de identificar se o sentimento é decorrente de problemas no curso ou da escolha equivocada da carreira profissional. Em relação à mobilidade e convênios, não podem ser considerados retenção negativa, sendo atividades que ampliam a experiência e a aprendizagem do aluno. Isso pode figurar num nível tolerável de retenção. Também podem se enquadrar nesse nível parte dos alunos que escolheram a quarta resposta (mais tempo para aproveitar melhor o curso), assim como alunos com problemas pessoais que não podem ser resolvidos pela instituição de ensino, mas que possuem interesse em se formar. 
Quando perguntados se já haviam pensado em desistir ou mudar de curso, $58,5 \%$ dos alunos responderam que não. Dos alunos que responderam ter vontade de desistir (41,5\%), a maior incidência ocorreu no primeiro semestre, diminuindo tal pensamento nos dois semestres seguintes, de acordo com o que apresenta a Tabela 8 .

Tabela 8 - Pensamento em desistir ou mudar de curso por parte dos alunos matriculados em 2011/1

\begin{tabular}{c|c|c}
\hline \multirow{2}{*}{ Opção } & \multicolumn{2}{|c}{ Frequência } \\
\cline { 2 - 3 } & Absoluta & Relativa (\%) \\
\hline Sim, no primeiro ano do curso & 41 & 19,8 \\
Sim, no segundo ano do curso & 27 & 13 \\
Sim, no terceiro ano do curso ou depois & 18 & 8,7 \\
Não & 121 & 58,5 \\
\hline Total & 207 & 100,0 \\
\hline
\end{tabular}

Fonte: Dados da pesquisa

De fato, as desistências ocorrem na maioria das vezes no início do curso (CARVALHO; PEROTA, 1990; MARTUCCI; NASTRI, 1990; BARDAGI; HUTZ, 2009), o mesmo já havia sido detectado no curso de Biblioteconomia da UFRGS na década de 1980 (KRUEL, 1988).

Quando perguntado aos alunos que já pensaram em desistir se ainda pensam, $86,6 \%$ (129 alunos) dos alunos responderam negativamente, demonstrando que os alunos que permanecem no curso se mantêm convictos de sua vontade de cursar. Com o intuito de confirmar a ideia acerca da desistência, os alunos em curso foram perguntados sobre a possibilidade de abandono. Apenas seis alunos $(2,9 \%)$ responderam que o abandono é muito provável, enquanto 162 alunos $(79,4 \%)$ responderam que é muito improvável.

A possibilidade de abandono pode estar relacionada à avaliação que o aluno do curso faz acerca do mercado de trabalho, que foi avaliado como muito bom por 49 alunos (23,7\%); bom (95 alunos, 45,9\%), razoável tendendo a bom (45 alunos, $21,7 \%$ ). A avaliação negativa do mercado de trabalho foi a opinião de 12 alunos (5,8\%). Apenas 6 alunos não souberam opinar sobre o assunto. 
Tal resultado indica que há motivação profissional para seguir nesta carreira profissional.

A Tabela 9 apresenta a motivação dos alunos, tanto os matriculados quanto os evadidos. Observa-se que alunos desmotivados e pouco motivados somam apenas $21,2 \%$ dos alunos em curso, enquanto para os alunos evadidos tal categoria corresponde a $69,1 \%$. Entre os alunos em curso há predomínio de respostas para a opção motivado $(62,3 \%)$, que somada aos que responderam muito motivados perfazem $78,8 \%$.

Tabela 9 - Motivação dos alunos evadidos e matriculados em 2011/1 em relação ao curso de Biblioteconomia da UFRGS

\begin{tabular}{c|cc|c|c}
\hline \multirow{2}{*}{ Espécie } & \multicolumn{2}{|c|}{ Evadidos } & \multicolumn{2}{c}{ Cursando } \\
\cline { 2 - 5 } & $\begin{array}{c}\text { Frequência } \\
\text { absoluta }\end{array}$ & $\begin{array}{c}\text { Frequência relativa } \\
(\%)\end{array}$ & $\begin{array}{c}\text { Frequência } \\
\text { absoluta }\end{array}$ & $\begin{array}{c}\text { Frequência } \\
\text { relativa (\%) }\end{array}$ \\
\hline Desmotivado(a) & 24 & 27,9 & 21 & 10,1 \\
Pouco motivado(a) & 36 & 41,9 & 23 & 11,1 \\
Motivado(a) & 20 & 23,3 & 129 & 62,3 \\
Muito motivado(a) & 6 & 7,0 & 34 & 16,5 \\
\hline Total & 86 & 100,0 & 207 & 100,0 \\
\hline
\end{tabular}

Fonte: Dados da pesquisa

A falta de motivação é uma das causas de evasão apontada nas pesquisas referentes a cursos de Biblioteconomia (KRUEL, 1988; CARVALHO; PEROTA, 1990; MARTUCCI; NASTRI, 1990; SOUZA, 1998). Apesar da pesquisa mais recente se referir a uma realidade de 15 anos atrás, essa causa parece ser ainda recorrente. A desmotivação pode ter diversas causas, questões pessoais, questões referentes ao curso ou ser fruto de uma escolha de carreira profissional feita sem muita certeza. Isso será melhor discutido mais adiante.

Em relação às percepções sobre o curso, alguns itens merecem destaque, como a decepção com conteúdos das disciplinas, apontada por $56,1 \%$ dos alunos como fator frequente ou com alguma frequência; a decepção com o cumprimento do plano de ensino, a decepção com o cumprimento da carga horária das disciplinas, a decepção com a grade curricular e a percepção de que o currículo do curso não proporciona uma formação consistente e atualizada. 
Tais resultados indicam a necessidade urgente de uma revisão das disciplinas e seus conteúdos, bem como a forma como eles estão sendo ministrados em sala de aula.

A dificuldade de conciliar horários do curso com outras atividades foi apontada por $10,9 \%$ dos respondentes como tendo impacto negativo no curso. A falta de tempo para se dedicar aos estudos também é um fator que mereceu destaque, visto que ela foi apontada como frequente para muitos respondentes.

Dificilmente um aluno abandona um curso superior por uma única razão, mas sim por um conjunto delas, e por isso as causas para a evasão discente são inúmeras. Os dados a seguir referem-se à pesquisa quanti-qualitativa com os alunos evadidos.

Ao ser questionada acerca da experiência acadêmica pregressa, grande parte $(45 \%)$ dos alunos evadidos do curso de Biblioteconomia relatou nunca ter iniciado outro curso superior, enquanto $39 \%$ já haviam iniciado ou tinham outro curso superior concluído.

O Gráfico 2 apresenta a relação do momento em que o aluno começou a pensar em desistir do curso com o nível de decisão pelo curso no momento de ingresso:

\section{Gráfico 2 - Relação entre a vontade de estudar Biblioteconomia e o semestre de desistência do curso}

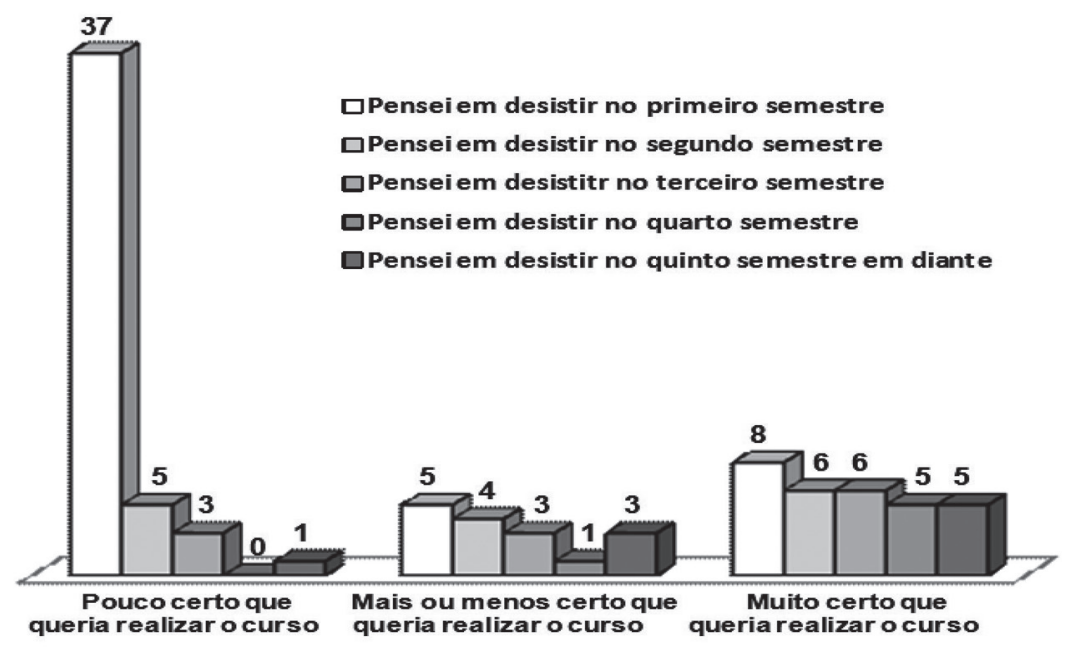

Fonte: Dados da pesquisa 
Observa-se que o aluno que estava pouco seguro de que queria cursar Biblioteconomia é aquele que pensou em desistir já no primeiro semestre. Esse resultado aponta para a necessidade de se fazer um trabalho específico de esclarecimento acerca do curso e da profissão no primeiro semestre, de forma que o aluno que não tiver interesse não permaneça matriculado por um longo período até a sua evasão.

Em relação ao semestre em que os alunos começaram a pensar em evadir do curso, destaca-se novamente que o primeiro é determinante, já que $49 \%$ dos alunos responderam que foi neste semestre que pensaram em desistir. O segundo semestre foi apontado por $18 \%$ dos alunos, e o terceiro por $14 \%$. Juntos, os três primeiros semestres foram apontados por $81 \%$ dos alunos evadidos, reiterando que a Coordenação do Curso de Biblioteconomia da UFRGS deve manter o foco e a preocupação nas disciplinas e alunos dos semestres iniciais.

Essa fragilidade na escolha da carreira profissional é um dos principais motivos que culmina na evasão, segundo Bardagi e Hutz (2009). De acordo com Veloso e Almeida (2001):

[...] a escolha da carreira por parte de egressos do ensino médio, frequentemente ainda imaturos para tanto, depende da discussão e de futura adoção de novas concepções de universidade, nas quais as opções profissionais possam ser feitas em época oportuna, para além dos constrangimentos que os atuais modelos de vestibular e de estudos universitários impõem à juventude.

Bardagi e Hutz (2009), assim como Veloso e Almeida (2001), salientam que a evasão pode ser vista como positiva nos casos em que é resultado de um amadurecimento pessoal e vocacional do aluno, com a troca de curso conduzindo-o a uma nova escolha de carreira. Contudo, os primeiros ressaltam que "[...] grande parte dos estudos aponta que o abandono de curso não está associado a novas escolhas e que as novas escolhas costumam também ser bastante frágeis e pouco consistentes." (BARDAGI; HUTZ, 2009, p. 96).

Essa fragilidade na escolha do curso superior pode também ser atribuída a pouco conhecimento acerca do curso e da profissão. O Gráfico 3 apresenta a relação entre a vontade de estudar Biblioteconomia e o nível de conhecimento acerca do currículo do curso.

Observa-se que quanto maior a vontade do aluno de cursar Biblioteconomia, maior é o nível de conhecimento do currículo e das possibilidades de atuação profissional. Tal resultado demonstra que a divulgação sobre o currículo e as possibilidades de trabalho podem auxiliar os alunos interessados, fazendo com 
que somente aqueles que realmente queiram cursar façam o vestibular, pois são estes que realmente se mantém no curso. A falta de informações prévias sobre curso e profissão é citada por alguns autores como uma das causas da evasão (ANDRIOLA, 2009; BARDAGI; HUTZ, 2009).

\section{Gráfico 3 - Relação entre a vontade de estudar Biblioteconomia e o nível de conhecimento acerca do currículo do curso}

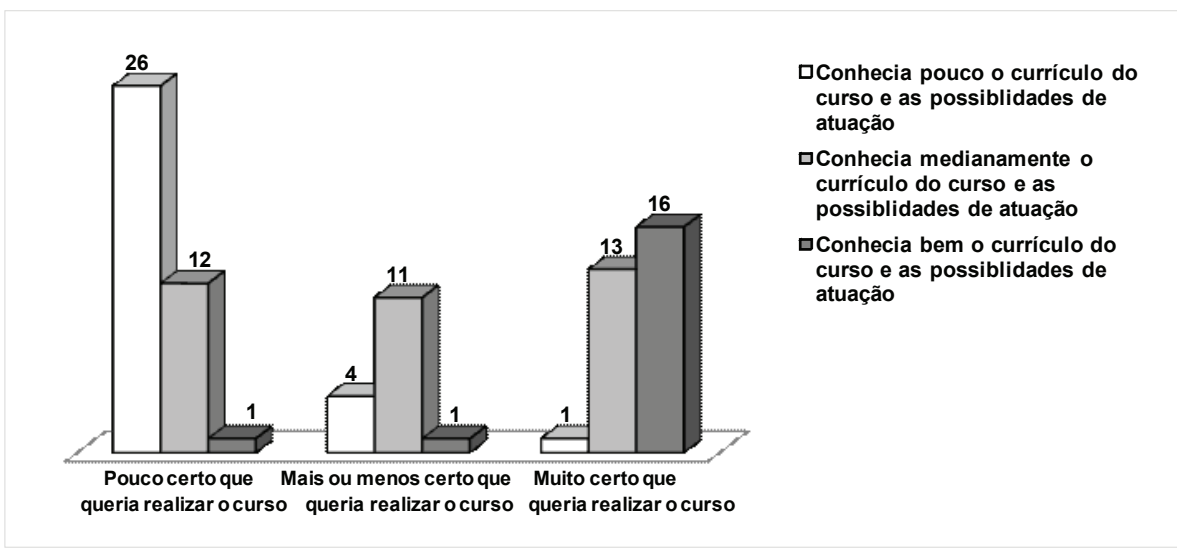

\section{Gráfico 4 - Objetivos do aluno evadido ao entrar no curso de Biblioteconomia}

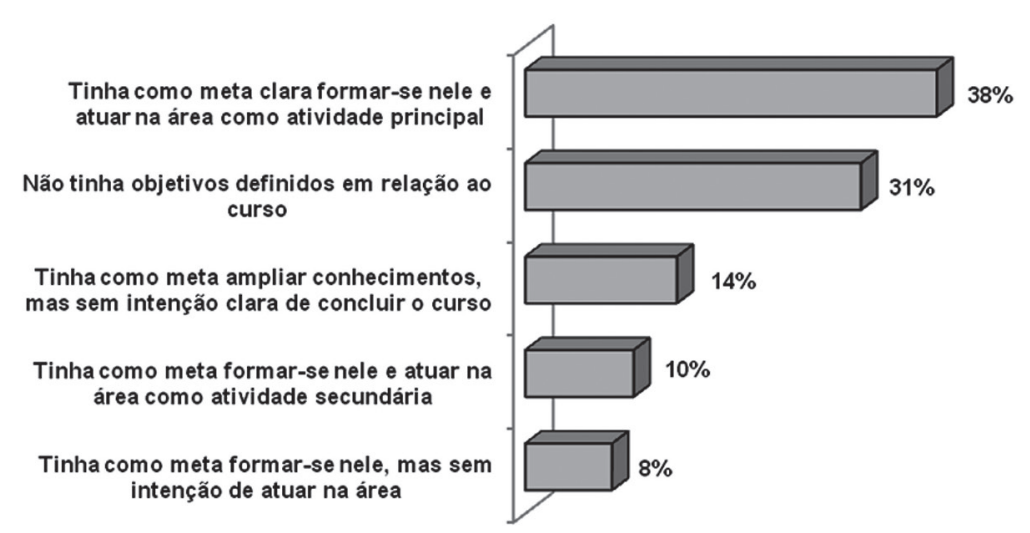

Fonte: Dados da pesquisa 
O Gráfico 4 apresenta os objetivos do aluno ao ingressar na Biblioteconomia. Os resultados indicam que $38 \%$ dos respondentes tinham como meta a formatura e a atuação profissional, enquanto $31 \%$ não tinham objetivos definidos. Chama a atenção que mais da metade dos alunos evadidos (56\%) tinha como meta concluir o curso. Isso reforça a ideia de que o aluno necessita receber maior apoio e atenção da instituição na resolução de problemas pessoais e institucionais, como forma de reduzir os níveis de evasão discente.

Durante as entrevistas, dos três alunos evadidos que ingressaram no curso com muita certeza de querer concluí-lo, dois afirmaram desejar voltar ao curso mesmo tendo optado pela evasão em determinado momento.

Em relação ao desempenho durante o curso, os alunos evadidos responderam ter desempenho pior, quando comparado com as respostas dos alunos em curso, conforme ilustra a Tabela 10.

Tabela 10 - Desempenho acadêmico dos alunos evadidos e em curso,
conforme avaliação do próprio aluno

\begin{tabular}{c|cc|c|c}
\hline \multirow{2}{*}{ Espécie } & \multicolumn{2}{|c|}{ Evadidos } & \multicolumn{2}{c}{ Cursando } \\
\cline { 2 - 5 } & $\begin{array}{c}\text { Frequência } \\
\text { absoluta }\end{array}$ & $\begin{array}{c}\text { Frequência relativa } \\
(\%)\end{array}$ & $\begin{array}{c}\text { Frequência } \\
\text { absoluta }\end{array}$ & $\begin{array}{c}\text { Frequência } \\
\text { relativa (\%) }\end{array}$ \\
\hline Muito ruim & 8 & 9,3 & 2 & 1,0 \\
Ruim & 13 & 15,1 & 14 & 6,8 \\
Razoável & 19 & 22,1 & 49 & 23,7 \\
Bom & 39 & 45,3 & 97 & 46,9 \\
Muito bom & 7 & 8,1 & 45 & 21,7 \\
\hline Total & 86 & 100,0 & 207 & 100,0 \\
\hline
\end{tabular}

Fonte: Dados da pesquisa

Ambos os grupos acreditam ter desempenho razoável e bom, entretanto os desempenhos muito ruim e ruim foram apontados por um número maior de alunos evadidos e, no extremo oposto, o desempenho muito bom foi mais indicado pelos alunos em curso.

Observa-se que 63 alunos evadidos trabalhavam enquanto estavam vinculados ao curso de Biblioteconomia, sendo que 65,1\% (41 respondentes) destes exerciam atividades não relacionadas ao curso e apenas $34,9 \%$ (22 respondentes) 
exerciam atividades relacionadas ao curso. Apenas 25 alunos não trabalhavam, conforme dados da Tabela 11.

\section{Tabela 11 -Vínculo de trabalho dos alunos evadidos}

\begin{tabular}{c|c|c}
\hline \multirow{2}{*}{$\begin{array}{c}\text { Existência de atividade de trabalho vinculada ao } \\
\text { curso de Biblioteconomia }\end{array}$} & \multicolumn{2}{|c}{ Frequência } \\
\cline { 2 - 3 } & Absoluta & Relativa (em \%) \\
\hline Sim & 22 & 34,9 \\
Não & 41 & 65,1 \\
\hline Total & 63 & 100,0 \\
\hline
\end{tabular}

Fonte: Dados da pesquisa

Nota: 25 evadidos alunos não trabalharam durante o curso

A pesquisa realizada no curso de Biblioteconomia na Universidade Federal do Espírito Santo (UFES) no período 1985 a 1995 também encontrou relação entre evasão e trabalho: "[...] observa-se que a incompatibilidade de horário entre trabalho e curso [...] contribui para o afastamento dos alunos do curso de Biblioteconomia; " (CARVALHO, PEROTA, 1990, p. 87). Esse é outro ponto delicado no que toca à evasão, a relação do aluno com o trabalho, devido a questões financeiras e necessidade de sustentar a si e/ou a sua família, como já foi mencionado anteriormente.

Em relação ao recebimento de bolsas durante a graduação, 78,4\% (69 alunos) afirmaram não ter recebido nenhuma bolsa. $\mathrm{O}$ restante dos alunos recebeu em sua maioria bolsa de estágio (10 alunos), iniciação científica ou outra (6 alunos) e bolsa Programa de Educação Tutorial (PET) (2 alunos). Percebe-se que o engajamento do aluno em atividades acadêmicas diversas pode ser um fator de decisão no momento da evasão, visto que estes resultados demonstram a baixa aderência dos alunos evadidos às atividades da universidade.

A necessidade de trabalhar é um aspecto bastante presente nas causas que figuram como importantes para a evasão, pois muitas vezes se torna difícil para o aluno conciliar os horários e as atividades de trabalho e estudo. Essa foi uma causa apontada por diversos autores, especialmente nos cursos de Biblioteconomia(CARVALHO; PEROTA, 1990; MARTUCCI; NASTRI, 1990; FERREIRA; TAZIMA; KRUEL, 2000), mas também de modo geral (ANDRIOLA, 2009; BARDAGI; HUTZ, 2009). 
A Tabela 12 apresenta o que o aluno evadido sentia em relação ao curso de Biblioteconomia da UFRGS.

\section{Tabela 12 - Sentimento do aluno em relação ao curso de Biblioteconomia da UFRGS}

\begin{tabular}{c|c|c}
\hline \multirow{2}{*}{ Sentimento } & \multicolumn{2}{|c}{ Frequência } \\
\cline { 2 - 3 } & Absoluta & Relativa (\%) \\
\hline Insatisfeito(a) & 33 & 37,9 \\
Pouco satisfeito(a) & 42 & 48,3 \\
Satisfeito(a) & 8 & 9,2 \\
Muito satisfeito(a) & 4 & 4,6 \\
\hline Total & 87 & 100,0 \\
\hline
\end{tabular}

Fonte: Dados da pesquisa

Observa-se que $86,2 \%$ dos alunos que se evadiram sentiam-se insatisfeitos ou pouco satisfeitos. O percentual de satisfação totalizava $13,8 \%$ apenas. Essa insatisfação pode ter relação tanto com a estrutura do curso como com uma não identificação com a área profissional. Em muitos casos a insatisfação é fruto de expectativas não correspondidas (BARDAGI; HUTZ, 2009), tanto com o curso como com a profissão e até com o sistema de ensino superior. Esses dados são aprofundados na etapa qualitativa da pesquisa, cujos resultados serão divulgados em publicação posterior.

Em relação às atividades realizadas após o abandono do curso de Biblioteconomia, cerca de $66 \%$ dos alunos ingressaram em outro curso superior e estão cursando ou já se graduaram. Esse fato indica que os alunos evadidos da Biblioteconomia tinham realmente interesse no ensino superior e, portanto, não se constituem em evadidos da educação universitária.

\section{Considerações finais}

Os resultados apresentados e analisados neste trabalho revelam as principais características determinantes da retenção e da evasão no curso de Biblioteconomia da UFRGS.

No geral, o aluno de Biblioteconomia tem boas expectativas quanto ao mercado de trabalho. Quanto maior a vontade do aluno de cursar Biblioteconomia, 
maior é o nível de conhecimento do currículo e das possibilidades de atuação profissional. E vice-versa.

Em relação aos resultados referentes aos alunos retidos no curso de Biblioteconomia, observou-se um índice superior a 40\% e a existência de alunos extremamente atrasados, com alto índice de reprovação por faltas e aproveitamento, múltiplos pedidos de trancamento e licenças saúde, baixo número de disciplinas cursadas por semestre e abandono/readmissão no curso.

Percebe-se que o trabalho do aluno representa grande influência na retenção no curso de Biblioteconomia da UFRGS, visto que $65,8 \%$ dos alunos apontaram como principal motivo os fatores relacionados ao contexto pessoal - dificuldade de conciliar o curso com trabalho (39,3\%) e responsabilidade com a família. Cerca de metade dos respondentes tem participação na renda familiar, resultado que indica grande responsabilidade por parte do aluno com relação à sua família. As famílias apresentam-se como de baixa renda, visto que 50\% delas têm renda inferior a 3,5 salários mínimos. Os alunos em curso apresentam considerável utilização de benefícios da universidade, sendo que $42,9 \%$ dos alunos chegam a utilizá-los durante 4 semestres do curso.

Em relação aos alunos evadidos, observa-se que o aluno que estava pouco seguro de que queria cursar Biblioteconomia é aquele que pensou em desistir já no primeiro semestre. Dos 88 alunos evadidos que responderam à pesquisa, 63 trabalhavam enquanto estavam vinculados ao curso de Biblioteconomia, sendo que $65,1 \%$ destes exerciam atividades não relacionadas ao curso. Os alunos evadidos responderam ter desempenho pior do que os cursando. Mais uma vez afirma-se que a necessidade de trabalhar é um fator que dificulta o desempenho acadêmico do aluno no curso de Biblioteconomia da UFRGS.

Entretanto, é importante ressaltar que $86,2 \%$ dos alunos que evadiram sentiam-se insatisfeitos ou pouco satisfeitos com o curso, demonstrando outros fatores além das dificuldades pessoais e familiares de conciliar horários. Outra prova disso é o fato de que $66 \%$ dos alunos que evadiram do curso de Biblioteconomia ingressaram posteriormente em outro curso superior e estão cursando ou já se graduaram. O aluno evadido é muito mais desmotivado, como mostrou a pesquisa. No entanto, a desmotivação pelo curso de Biblioteconomia não representa a falta de interesse pelo ensino superior. O desempenho da maioria dos alunos fica em uma faixa mais que aceitável, sendo que muitos deles ingressam e finalizam outras graduações após terem se evadido do curso de Biblioteconomia. 
Observou-se que a iniciativa para desistir e de fato, a desistência, acontece logo no início do curso, especialmente no primeiro semestre. Neste sentido, a coordenação do curso pode procurar desenvolver um trabalho motivacional e de informação sobre o curso e a carreira profissional com alunos do primeiro e segundo semestres.

Ao longo do curso também é preciso destinar mais apoio ao aluno, acompanhamento e orientação, para ajudá-lo com procedimentos na universidade que o ajudem a driblar os problemas pessoais e institucionais. A UFRGS conta com o apoio de profissionais pedagogos (Técnico em Assuntos Educacionais) desde 2011 para apoiar a Coordenação dos cursos de graduação. Estes profissionais podem trabalhar no acompanhamento dos alunos e orientação vocacional no caso de dúvidas quanto à escolha profissional.

Orientações prévias e realistas para os potenciais alunos também poderiam ser veiculadas durante as atividades de apresentação da universidade para a comunidade, como o UFRGS Portas Abertas, atividade anual que recebe alunos potenciais advindos dos cursos de Ensino Médio de Porto Alegre e do interior do Estado.

A pesquisa realizada no curso de Biblioteconomia da UFRGS gerou conhecimentos que poderão subsidiar ações e estratégias voltadas à minimização tanto da evasão quanto da retenção discentes, auxiliando no aprimoramento das condições de ensino. Ao mesmo tempo, espera-se possibilitar a ampliação do debate no contexto das graduações em Biblioteconomia no país.

\section{Referências}

ANDRIOLA, Wagner. Fatores associados à evasão discente na Universidade Federal do Ceará (UFC) de acordo com as opiniões de docentes e de coordenadores de cursos. Revista Iberoamericana sobre Calidad, Eficacia y Cambio en Educación, Madrid, v. 7, n. 4, p. 343-356, 2009.

ARAUJO, Carlos Alberto Ávila; MARQUES, Angélica Alves da Cunha; VANZ, Samile Andréa de Souza. Arquivologia, Biblioteconomia e Museologia integradas na Ciência da Informação: as experiências da UFMG, UnB e UFRGS. Ponto de Acesso, Salvador, v. 5, n. 1, p. 85-108, 2011.

BARDAGI, Marúcia Patta; HUTZ, Cláudio Simon. "Não havia outra saída": percepções de alunos evadidos sobre o abandono do curso superior. PsicoUSF, Bragança Paulista, v. 14, n. 1, p. 95-105, jan./abr. 2009. 
BELMONTE, Ema Reginatto. UFRGS enfrenta alto índice de evasão. Correio do Povo, Porto Alegre, 31 mar. 2003. Disponível em: <http://www. correiodopovo.com.br/jornal/A108/N182/HTML/09UFRGS9.htm>. Acesso em: 14 abr. 2010.

CAMPELLO, Antonio de Vasconcellos Carneiro; LINS, Luciano Nadler. Metodologia de análise e tratamento da evasão e retenção em cursos de graduação de instituições federais de ensino superior. In: ENCONTRO NACIONAL DE ENGENHARIA DE PRODUÇÃO, 2008, Rio de Janeiro. ABEPRO.

CARVALHO, Isabel Cristina Louzada; PEROTA, Maria Luiza Loures Rocha. A evasão dos alunos do curso de Biblioteconomia da Universidade Federal do Espírito Santo. Revista da Escola de Biblioteconomia da UFMG, Belo Horizonte, v. 19, n. 1, p. 78-93, mar. 1990.

CESARINO, Maria Augusta da Nóbrega; KREMER, Jeannette Marguerite; DUMONT, Márcia Milton Vianna; SIMÕES, Eliedir Marcelina dos Santos. A retenção de alunos por infrequência, aproveitamento e trancamento de matrícula no curso de graduação de Biblioteconomia da Universidade Federal de Minas Gerais. Revista da Escola de Biblioteconomia da UFMG, Belo Horizonte, v. 16, n. 2, p. 159-190, set. 1987.

\section{DALLA ZEN, Ana Maria (Coord.). Avaliação do Curso de}

Biblioteconomia da UFRGS: contexto, entrada, processo e produto. Porto Alegre: UFRGS/NEBI, 1986.

FERREIRA, Glória Isabel Sattamini; TAZIMA, Ivete Hissako; KRUEL, Inês Rosito Pinto. Variáveis possíveis de evasão no curso de Biblioteconomia da Universidade Federal do Rio Grande do Sul: identificadas pelos alunos matriculados em 1995. Revista de Biblioteconomia \& Comunicação, Porto Alegre, v. 8, n. 1, p. 135-142, jan./dez. 2000.

GIL, Antônio Carlos. Métodos e técnicas da pesquisa social. 5. ed. São Paulo: Atlas, 2007.

KRUEL, Inês Rosito Pinto. Evasão no curso de Biblioteconomia da UFRGS, 1979-86. Revista de Biblioteconomia \& Comunicação, Porto Alegre, v. 3 p. 67-78, jan./dez. 1988. 
LOBO, Maria Beatriz de Carvalho Melo. Panorama da evasão no ensino superior brasileiro: aspectos gerais das causas e soluções. In: INSTITUTO LOBO PARA DESENVOLVIMENTO DA EDUCAÇÃO, DA CIÊNCIA E DA TECNOLOGIA (Org.). Instituto Lobo. São Paulo, 2012. Disponível em: $<$ http://www.institutolobo.org.br/imagens/pdf/artigos/art_087.pdf $>$. Acesso em: 20 jul. 2013.

MARTUCCI, Elisabeth Márcia; NASTRI, Rosemeire Marino. Análise da evasão e retenção escolar na EBDSC: 1985-1989. Revista Escola de Biblioteconomia da UFMG, Belo Horizonte, v. 19, n. 1, p. 59-77, mar. 1990.

OLIVEIRA, Lizete Dias; ROCHA, Rafael Port da. Da fragmentação da informação à integração: o caso dos cursos de arquivologia, biblioteconomia e museologia da Universidade Federal do Rio Grande do Sul. In: FRIAS, J.A.; TRAVIESO, C. (Org.). Formação, investigação e mercado de trabalho em informação e documentação em Espanha e Portugal. Salamanca: Ediciones Universidad de Salamanca, 2008. p. 387-399.

SANTOS, Jussara Pereira; SILVEIRA, Itália Maria Falceta da. FABICO: fragmentos de uma trajetória. Revista de Biblioteconomia e Comunicação, Porto Alegre, v. 8, p. 275-290, jan./dez. 2000.

SILVA FILHO, Roberto Leal Lobo; MONTEJUNAS, Paulo Roberto; HIPÓLITO, Oscar; LOBO, Maria Beatriz de Carvalho Melo. A evasão no ensino superior brasileiro. Cadernos de Pesquisa, São Paulo, v. 37, n. 132, p. 641-659, set./dez. 2007.

SOUZA, Francisco das Chagas. Movimento estudantil em Biblioteconomia: um olhar sobre a UFSC ou a importância do movimento estudantil para a formação profissional. Encontros Bibli, Florianópolis, n. 6, set. 1998.

VELLOSO, Jacques; CARDOSO, Claudete Batista. Evasão na educação superior: alunos cotistas e não-cotistas na Universidade de Brasília. In: REUNIÃO ANUAL DA ANPEd, 31., 2008, Caxambú. Anais... Associação Nacional de Pós-Graduação e Pesquisa em Educação.

VELOSO, Tereza Christina M. A.; ALMEIDA, Edson Pacheco de. Evasão no cursos de graduação da Universidade Federal de Mato Grosso, Campus Universitário de Cuiabá: um processo de exclusão. In: REUNIÃO DA ANPEd, 24., 2001, Caxambú. 
Samile Andrea de Souza Vanz - Universidade Federal do Rio Grande do Sul | Porto Alegre | RS | Brasil. Contato: samilevanz@terra.com.br

Patrícia Mallmann Souto Pereira - Universidade Federal do Rio Grande do Sul | Porto Alegre | RS | Brasil. Contato: patriciamall@yahoo.com.br

Glória Isabel Sattamini Ferreira - Universidade Federal do Rio Grande do Sul | Porto Alegre | RS | Brasil. Contato: gloria.ferreira@ufrgs.br

Geraldo Ribas Machado - Universidade Federal do Rio Grande do Sul Porto Alegre | RS | Brasil. Contato: geraldo.machado@ufrgs.br

Artigo recebido em 27 de novembro de 2013 e aprovado em 19 de maio de 2014. 